\title{
INVITATION TO CANADIANS WHO ARE STUDYING MATHEMATICS OUTSIDE CANADA
}

The undersigned believe that many Canadian mathematicians who are completing their doctoral work outside Canada would be interested to return to Canada if they received offers from Canadian universities as attractive as the other offers which they receive. We believe also that Departments of Mathematics at Canadian universities would welcome information as to which Canadian students abroad are completing their doctoral work.

With this in mind, we propose to make a systematic effort to improve contact between Canadian mathematicians who are outside Canada and the Canadian university departments of mathematics.

We invite each Canadian studying mathematics outside Canada to send us, as soon as he begins his thesis, a note stating his special field of interest, thesis area, name of institution, name of supervisor, estimated date for completing $\mathrm{Ph} . \mathrm{D}$., date and place of B. A. or B.Sc.

Teachers or friends of Canadians who are studying outside Canada are asked to pass on this invitation.

We do not propose to engage in a great deal of correspondence. But we believe a little effort will produce results beneficial both to the students who have gone outside Canada for graduate work and to Canadian universities.

C. Davis and I. Halperin, Professors of Mathematics, The University of Toronto. 